Jurnal Keperawatan Padjadjaran

ISSN 2338-5324 (print)

ISSN 2442-7276 (online)

Online di http://jkp.fkep.unpad.ac.id

DOI : $10.24198 / \mathrm{jkp}$

\title{
The Nurses' Experience during the Caring of Coronavirus (COVID-19) Patients: A Descriptive Qualitative Study
}

\author{
Indah Sri Wahyuningsih ${ }^{1}$, Fitria Endah Janitra ${ }^{2}$, Rebriarina Hapsari ${ }^{3}$, Sarinti Sarinti ${ }^{4}$, \\ Muhammad Mahfud ${ }^{5}$, Failasuf Wibisono ${ }^{6}$ \\ ${ }^{1,2}$ Faculty of Nursing, Islamic Sultan Agung University, Semarang, Indonesia \\ ${ }^{3}$ Faculty of Medicine, Diponegoro University, Semarang, Indonesia \\ ${ }^{4}$ Critical Care Nurse, Tugurejo Hospital, Semarang, Indonesia \\ ${ }^{5}$ Emergency Nurse, Islamic Sultan Agung Hospital, Semarang, Indonesia \\ ${ }^{6}$ Critical Care Nurse, Roemani Muhammadiyah Hospital, Semarang, Indonesia \\ Corresponding Email: indah.unissula@gmail.com
}

Submitted: 20-11-2020 Accepted: 21-12-2020 Published: 27-12-2020

\begin{abstract}
COVID-19 transmission in the hospital environment can be catalized by a direct contact and droplets. Nurses are at the forefront of having the longest contact with the infected patient during the treatment. This research aims to dig on the deep meaning on the nurses' practice during treating the COVID-19's patients. This is a qualitative research design with a descriptive explorative approach. The sampling technique used in this research was a purposive side. The Data collection were carried out on five nurses who were in charge of caring the COVID-19 patients at two Semarang city's hospitals. The research data were in the form of conversation transcripts which were analyzed using content analysis. This qualitative research analysis brought the results in three themes: first, the challenge of being a COVID-19 nurse in the emergency room, ICU and Covid care room, second, the resilience and resilience of nurses, third, the professionalism of nurses. This study indicate that the experience of nurses caring for COVID-19 patients has many challenges, namely fatigue, discomfort, anxiety, fear of contracting and stress. Anxiety creates psychological problems for nurses, which reduces the quality of service during the pandemic. Resilience and toughness are the main foundations for nurses during the pandemic. There is a need for further research with qualitative methods to look at the factors that impact on successful nursing care in COVID-19 patients during the pandemic.
\end{abstract}

Keywords: COVID-19 patients, professionalism, self toughness, the nurses's challenge. 


\section{Introduction}

Corona viruses 2019 (COVID-19) is caused by SARS-CoV-2 infection) (Chen et al., 2020). COVID-19 have been diagnosed in Wuhan since December 2019, with a total of 101,927 confirmed in March 2020. The number of patients infected with COVID-19 continues to increase in several countries, one of the countries with the COVID-19 pandemic case is Indonesia. The number of confirmed COVID-19 cases continued to grow; 4,241, 3509 treated with a total of 373 positive cases and 359 recoveries (Satgas Penanganan COVID-19, n.d.).

The transmission of medical personnel from COVID-19 comes from nosocomial infections that are obtained from the hospital environment from a direct contact and droplets. One of the chains of transmission of the COVID-19 virus infection is through human-to-human transmission and droplets, not all hospitals have sufficient equipment for personal protection. The number of patients infected with the virus continues to grow rapidly in Wuhan, China (Wu et al., 2020). Most of the patients infected with COVID-19 with symptoms of fever and cough are followed by shortness of breath, fatigue, joint pain, dyspnea, dizziness and diarrhea (Chen, Lai, \& Tsay, 2020). The limited number of personal protective equipment causes the spread of the Corona virus to occur in health workers who treat COVID-19 patients. The data shows that as of April 14, 2020, there were 28 doctors died and 13 nurses died while handling COVID-19. However, there are challenges that must be faced by health workers, namely the emergence of a stigma in Indonesia that there is rejection of doctors and nurses in their homes because they are considered the source of the virus. The existence of this can cause other problems among professionals is depression and feeling useless (Gunawan, Juthamanee, \& Aungsuroch, 2020). This is opposite to the role of nurse as vanguard during the pandemic.

Nurses are health professionals who are at the forefront of dealing with COVID-19 patients who work in acute care rooms, home care, schools, communities and governmentowned health practices (Chen et al., 2020).
Nurses have multiple roles and functions during the COVID-19 pandemic. The role and function of nurses is indispensable during a pandemic. Nurses need to have special skills in caring for COVID-19 patients during the pandemic. In essence, COVID-19 patients need supportive care, especially the expertise, knowledge, attitudes and skills of nurses (Karimi et al., 2020). Lack of health facilities and personnel creates confusion in providing care for patients. The transmission of COVID-19 is very fast and widespread, thus, the consequence is that health workers must be strong in treating patients. Nurses as the frontline have a greater risk of contracting the COVID-19 disease. Doctors and nurses as vanguards who do not have special expertise in caring for infectious patients have great challenges in caring for patients and working adjustment in pandemic situations (Liu et al., 2020). This study aims to explore the meaning and meaning in depth about the experiences of nurses while caring for COVID-19 patients.

\section{Method}

This research design was under the qualitative method with a descriptive explorative approach. The process of descriptive explorative methodology includes four steps: bracketing, intuiting, analyzing, and describing (Polit \& Hungler, 2012). This study involves at nurses' experiences while caring for COVID-19 patients. The sampling technique in this study was purposive sampling with the inclusion criteria of nurses who were assigned to care for COVID-19 patients, were willing to be interviewed and agreed to be research participants. Sampling is not sufficient in one data collection; however, it is carried out until the saturation of the data is obtained. The study was conducted from 20 May to 21 June 2020 with participants being nurses at the Semarang City Hospital. Participants who were interviewed were 5 nurses caring for COVID-19 patients. Ethics approval was obtained from the Human Ethics Committee of Sultan Agung Islamic Hospital.

The data has been written can be written completely in accordance with the results of interviews with respondents, to ensure the 
trustworthiness researchers use triangulation techniques. It has using data checking techniques in the data collection process in order to show a degree of trust. Researchers used this technique by returning the interview data that had been processed by the researcher to the participants. The data was submitted of participants become checked again in order to obtain a conformity between the written interview data and the participants' perceptions.

Researchers explored the participants using semi-structured questions. Interviews were conducted for each participant with a duration of between 50- 70 minutes. Indepth interviews were conducted with telecommunications media and did not meet face-to-face and had the consent of the participants. Interviews were conducted with telecommunications media by adjusting the participants' spare time.

The researcher wrote the results of the interview and documented it in the form of a transcript which was then analyzed using content analysis. The main questions posed to participants included; describing their experience while treating patients with COVID-19, then interviews are conducted based on answers from participants, in-depth questions such as, "Whats next", "could you can explain". Although the various questions were carried out in depth from the answers of the participants, the researchers still conducted interviews according to the guidelines so that the questions remained in accordance with the desired objectives.

The results of interviews with participants were analyzed using content analysis. Content analysis consists of making a transcript of the nurse's conversation with the patient, determining the meaning of each unit to look for relationships between words, sentences or paragraphs, and then abstracting the data to form several themes. The implementation of this qualitative research was using ethical principles of research.

\section{Results}

\section{Characteristics of Participants}

As shown in Table 1. The participants of this study were 5 nurses; 3 men and 2 women with a mean age of $31.8 \pm 6.91$ and work experience of $8 \pm 5.34$ (Table 1).

Tabel 1 Characteristic of Partisipants

\begin{tabular}{lcccccc}
\hline $\begin{array}{c}\text { Number of } \\
\text { partisipants }\end{array}$ & Age & Sex & $\begin{array}{c}\text { Level of } \\
\text { Education }\end{array}$ & Ward & $\begin{array}{c}\text { Work } \\
\text { Experience }\end{array}$ & Position \\
\hline P1 & 24 years & Female & Bachelor & ICU & 2 years & Nurse \\
P2 & 35 years & Female & Bachelor & Emergency & 10 years & Nurse \\
P3 & 29 years & Male & Bachelor & ICU & 5 years & Nurse \\
P4 & 29 years & Male & Bachelor & Infectious & 7 years & Nurse \\
P5 & 42 years & Male & Bachelor & ICU & 16 years & Nurse \\
M \pm SD & $31.8 \pm 6.91$ & - & - & - & $8 \pm 5.34$ & - \\
Total & $\mathrm{N}=5$ & & & & & \\
\hline
\end{tabular}

The results of the research analysis produced three themes and eight sub theme from the participants. The first theme of this research is the challenge of being a COVID-19 nurse in the emergency room, ICU and COVID care room, the second is the resilience and resilience of nurses, the third is the professionalism of nurses. The following is an explanation of the research analysis:

The first theme is the challenge of being a COVID-19 nurse in the emergency room, ICU and Covid care room.
The nurse who is caring for COVID-19 patients has several experiences. Participants explained that caring for COVID-19 patients presented physical and psychological challenges.

\section{Sub theme 1.1: Uncomfortable feeling}

Data analysis shows that nurses caring for COVID-19 patients have experiences with high levels of stress and anxiety. The data shows that nurses experience psychological distress. Participants said that serving in the 
Covid team must always think positively, because each task must see patients who experience shortness of breath. In essence, participants also felt short of breath when they had to be on duty and wore level 3 personal protective equipment.

"... yes it is tight ma'am, but yes, when I am emptying, I try to sit down ma'am" (P1) Another participant also revealed,

"I felt dizzy, I felt so hot when I used hazmat that I started to sweat, even though in an air-conditioned room ..."(P5)

\section{Sub theme 1.2: Overloaded work}

Analysis of the data shows that nurses caring for COVID-19 patients feel very tired. Nurses are tasked with providing full nursing care because of the level of dependence of COVID-19 patients. The limited number of nurses on the Covid team and the increasing number of patients caused nurses to experience fatigue because they had to provide complete nursing care.

One of the participants said "... it was very tiring, my chest was pounding and I felt dizzy, when I took a patient to Radiology wearing a hazmat suit ...”(P3)

Other participants also said that the Covid team always went home beyond shifts because they had to meet the patient's basic needs such as helping to feed, giving medication, because no family was waiting.

“... our patients are always full ma'am, every time shift 1 the nurse holds 3 to 4 patients with a high level of dependence ..."(P4).

\section{Sub theme 1.3: Adequacy of personal protective equipment (PPE)}

Data analysis showed that nurses experienced limitations in the need for PPE use. Participants said that in using PPE, efforts were made to be economical so as not to be wasteful. In addition, in pandemic conditions, the use of N95 masks can be reused after taking action as long as they are not wet.

“... Yes ma'am, so as not to be wasteful of N95 masks, which are said to cost hundreds of thousands ..." (P3)

"... at our place in the ICU, after wearing the N95 mask, you can store the mask, put the prepared paper bag and mark the paper bag so you don't beat other friends.”(P1)

"... Alhamdulillah, in our emergency room, the PPE is still sufficient even though the number of PDP patients is increasing" (P2)

\section{The second theme is self-resilience}

The experience of the participants shows that as a frontline nurse you must be mentally and physically prepared. Participants said they had to be well-nourished and rested even though the activities were very high and tiring. In essence, during the pandemic, the use of PPE is in accordance with the established protocol, the participants are committed to their work as the vanguard, so that in wearing PPE they always comply with the correct wear and take off protocol.

\section{Sub theme 2.1 The effect of the PPE material so thin}

Participants explained that as a frontline nurse, using PPE is very important while caring for COVID-19 patients. The availability of PPE is made of thin material so that during the disinfecting process, the liquid enters the PPE and the clothes that wear get wet. It makes nurses still have to be strong during a pandemic. The participants explained as follows:

"... Yes ma'am, if you get the thin one, wow if you want to spray disinfectant at the end, it will enter the part of his official shirt ..." (P1)

\section{Sub theme 2.2 Increase self resilience and immunity while caring patient}

Nurses need self resilience and toughness during treatment for patients so they need vitamins and supplements after caring patients. It was explained by the participants as follows:

"... drinking enough warm water, incidentally honey and vitamin supplements are available so that they can meet the needs of the body" (P5)

\section{The third theme is the professionalism of nurses}

Success in treating patients is indicated by good or professional work performance. Participants said that while caring for COVID-19 patients, good collaboration 
Indah Sri Wahyuningsih: The Nurses' Experience during the Caring of Coronavirus (COVID-19) Patients

between teams is needed so that collaboration can be provided in providing nursing care to patients. Participants said that when treating Covid patients, they must be able to work together with the team. For example, when caring for patients in the ICU, peer collaboration is needed so that the patient's basic needs are met.

\section{Sub theme 3.1 Collaboration of team}

The good quality of nursing service is supported by teamwork in providing services for the basic needs of patients. It was explained by the participant as follows:

"...We are a team, such as guarding the six of them, so two friends meet the basic needs of the patient in the isolation room, two more nurses are outside as operators are monitoring the program from CCTV, and two outside nurses are in charge of completing the nursing documentation". (P4)

\section{Sub theme 3.2 sympathy and concern between team}

When installing PPE, assistance between colleagues is also needed to make it suitable in using PPE. Peer support is also needed during the COVID-19 pandemic. Participants feel they get support from friends so that

"... after doing the program in the patient's room, when I came out and cleaned up, I was so touched that my boss made me a drink of warm honey (P5).

"When wearing and taking off the hazmat suit, friend and others help each other when wearing it ..." (P1)

\section{Sub theme 3.3 Communication between team}

Professionalism in nursing services need good communication between teams in order to achieve quality of service. During a pandemic, a special team is needed to communicate in caring COVID-19 patients. It was explained by the participants as follows:

"... it is very important to learn nursing management on respiratory system problems like COVID-19, ma'am, we have a covid task force team as a forum for communication during a pandemic" (P2).

\section{Discussion}

This research is a type of qualitative research conducted during the COVID-19 pandemic. This study describes the experience of nurses caring for COVID-19 patients in the emergency room, ICU and Covid inpatient rooms. The results showed that as a COVID-19 nurse in the emergency room, ICU and Covid care room, there were many challenges, including feelings of discomfort, overloading of work and adequacy of PPE. The results showed that nurses felt uncomfortable and anxious while caring for COVID-19 patients due to the increasing number of patients identified with Covid with symptoms of shortness of breath. The increasing number of patients which increases every day causes an increase in the workload of nurses. The pandemic period in China resulted in a lack of critical nurses caring for COVID-19 patients, less logistical problems such as a lack of personal protective equipment such as gloves, eye protection, gowns and disposable instruments (Xie et al., 2020). In essence, the job of nurses with a high burden, consequently, the patient will also be less in his care (Ross, Bevans, Brooks, Gibbons, \& Wallen, 2017).

The results of the analysis of this study also stated that the high workload due to additional service hours was a challenge for nurses in the frontline. This is in line with the problems that occurred in Barcelona during the pandemic, nurses were scheduled to be more monthly by postponing the proposed leave schedule, the hospital recruiting new nurses who have expertise and experience in critical nursing (Raurell-Torreda, 2020). Nurses in China during the pandemic also experienced a change in hours during service, namely an additional one hour per shift (Huang, Lin, Tang, Yu, \& Zhou, 2020). An increase in workload during a pandemic has an impact on the emergence of psychological problems for health workers. Nurses, doctors and staff in hospitals face enormous pressure during their duties in caring the patient. A heavy workload is a major factor in stress and other psychological problems. The rapid increase in the number of patients causes the workload of nurses to increase and the occurrence of 
fatigue in nurses. A heavy workload often creates other problems for nurses including headaches, difficulty sleeping and high blood pressure (Chow et al., 2020).

The result this study also showed that nurses caring for COVID-19 patients felt tired while on duty, the participants explained that their working hours always exceeded their service time because they helped the patient's basic needs so they always went home not on time. This fatigue causes dizziness, palpitations, anxiety and stress during work. Another study said that the high workload of nurses causes nurses to make mistakes in providing nursing care to patients, due to rushing to take nursing action, wearing personal protective clothing, fear of contracting, stress and anxiety that dominate the work environment (Galedar, Toulabi, Kamran, \& Heydari, 2020).

Nurses caring for COVID-19 patients have different experiences and perceptions. Individual perceptions may be different, because the stimulus received by each individual is not the same. Feelings, thinking abilities, experiences that are owned by individuals which different so that in understanding the stimulus, each individual will be different (Wulandari \& Ismail, 2019). This makes different perspectives a natural thing to happen, so a communication forum between teams is needed during a pandemic. Communication skills are important and must be continuously improved by every nurse, so that they become a habit in carrying out their duties in providing health services in hospitals (Emaliyawati, Widiasih, Sutini, Ermiati, \& Rahayu, 2020). The results of this study indicate that participants need good communication between teams while caring for COVID-19 patients in order to achieve quality nursing care. The communication method that can be carried out during a pandemic is telecommunications

Health workers need telecommunications virtually to overcome psychological problems. Symptoms that appear in most health workers are fatigue and fatigue of the mind. Health workers working in isolation rooms are worried that they will catch COVID-19 patients. During the SARS epidemic, some health workers were infected (Schwartz, King, \& Yen, 2020). Health workers need psychoeducation to deal with post-traumatic problems, anxiety and depression during a pandemic (Ornell, Halpern, Paim Kessler, \& de Magalhães Narvaez, 2020). The problem that arises among health professionals in Indonesia is that doctors and nurses feel there is a stigma in society that considers health professionals to be the source of the virus. In addition, health workers, namely doctors and nurses, feel useless and depressed because they felt not appreciated (Gunawan et al., 2020).

This is also in line with the results of this study where fatigue is a challenge for nurses caring for COVID-19 patients during the pandemic. Participants conveyed that they were tired because of wearing thick personal protective clothing and it can cause difficulty breathing. The existence of psychological pressure and social burdens experienced by health workers when treating patients is very necessary for policy makers to pay attention to, so that health workers receive physical and psychological support to prevent the spread and manage the transmission of this disease outbreak in the scope of health workers (Chen et al., 2020). In line with the findings of this study, other studies have shown that an increase in the number of patients during the COVID-19 pandemic has resulted in nurses working hours increasing by about 1.5-2 times than normal. Apart from increasing working hours, the workload has also increased (Liu et al., 2020).

Data analysis on the second theme of the study is the self-resilience of nurses in caring for COVID-19 patients. Nurses as the vanguard must be able to manage themselves well during a pandemic. The problem often faced by nurses in the vanguard is anxiety. Anxiety will lead to infection, stress with workload, depression and fear of nurses which will lead to the transmission of infection to the family. In addition, during this pandemic, nurses are required to maintain their resilience as the frontline by using personal protective equipment (PPE) (Al Thobaity \& Alshammari, 2020). The results showed that the participants were always committed to adherence to using PPE while treating COVID-19 patients. During a pandemic, the use of PPE needs to be regulated so that 
Indah Sri Wahyuningsih: The Nurses' Experience during the Caring of Coronavirus (COVID-19) Patients

it is always sufficient. The use of PPE is adjusted to the correct PPE usage protocol or technical guidelines. Several research results show that COVID-19 is transmitted through close contact and droplets. Health workers can protect themselves while caring for patients by complying with infection control and prevention practices with the use of proper personal protective equipment (Wibowo, Bambang, Widyastoeti, Tri Hesty, Satari, 2020). However, the use of personal protective clothing or hazmat suits in this study shows that there is a problem related to the thin hazmat base material that will cause nurses to feel uncomfortable because when disinfecting is sprayed sometimes it gets into the nurse's official clothes. The results of this study are in line with other qualitative research which states that there is inadequate access to nurse protective clothing such as damage to personal protective clothing(Galedar et al., 2020). Personal protective equipment that is used while treating patients required thick material but comfortable to use. If the quality of the material is good, it will have a positive impact, namely a sense of comfort at work so that it does not overheat while working. The feeling of comfort will make nurses enthusiastic and not easily tired because the materials used are not hot.

The results of data analysis on the third theme of this study are the professionalism of nurses. The results showed that cooperation and support between peers was needed during the COVID-19 pandemic to have an important role in the self-development of nurses. With good teamwork, patients will get satisfaction from the care that has been provided by the health team. Providing less nursing care will have an impact on patient satisfaction in getting services at the hospital. Nurse support is able to bring out good experiences in patients while being treated (Lake, Germack, \& Viscardi, 2017). The importance of teamwork in patient care will make teamwork effective and a major component in improving the quality of health services (Findyartini et al., 2019). Having a nurse professional attitude is an important opportunity for nurses during this pandemic. Data analysis shows that every nurse needs to know nursing care for patients with respiratory problems such as COVID-19. The existence of this pandemic incident made nurses have positive experiences and became responsible for being able to contribute to society. This is evident from qualitative research which states that even though they are under psychological pressure, nurses still provide the best nursing care and feel very touched when the patients they treat are cured (Karimi et al., 2020).

The condition of the COVID-19 pandemic is an opportunity for nurses to develop professional nursing science in a way of loving each other, respecting the profession, giving thanks to the people around them and active cooperation during patient care with COVID-19 (Sun et al., 2020). Research analysis shows that nurses need full support from policy makers in order to provide health services during a pandemic by providing financial support and spiritual support so that health workers get good protection.

\section{Conclusion}

The results of this study indicate that the experience of nurses caring for COVID-19 patients has many challenges, namely fatigue, discomfort, anxiety, fear of contracting and stress. Anxiety creates psychological problems for nurses, which reduces the quality of service during the pandemic. Resilience and toughness are the main foundations for nurses during the pandemic. The number of COVID-19 patients, which continues to increase every month, has made health centers, especially nurses, can take advantage of opportunities by increasing professionalism in providing nursing care to COVID-19 patients. The role of policy holders is very necessary to be able to facilitate nurses such as virtual psychoeducation, meeting the needs for adequate personal protective equipment, procurement of it with basic materials that are comfortable and not hot so that nursing care to COVID-19 patients properly.

The limitation in this study is that data collection is done face-to-face online, and cannot meet in person due to the implementation of strict health protocols during the pandemic period. However, researchers are trying to be able to foster 
communication with participants through taking data by telephone and there is evidence of conversation transcripts so that the research can still be carried out effectively. There is a need for further research with qualitative methods to look at the factors that affect nursing care in COVID-19 patients during the pandemic.

\section{References}

Al Thobaity, A., \& Alshammari, F. (2020). nurses on the frontline against the COVID-19 pandemic: An integrative Review. Dubai Medical Journal, 3(3), 1-6. https://doi. org/10.1159/000509361

Chen, S. C., Lai, Y. H., \& Tsay, S. L. (2020). Nursing perspectives on the impacts of COVID-19. Journal of Nursing Research, 28(3), 1-5. https://doi.org/10.1097/ NRJ.0000000000000389

Chen, Zhou, Dong, Qu, Gong, Han, Y., ... Zhang, L. (2020). Epidemiological and clinical characteristics of 99 cases of 2019 novel coronavirus pneumonia in Wuhan, China: a descriptive study. The Lancet, 395(10223), 507-513. https://doi. org/10.1016/S0140-6736(20)30211-7

Chow, K. M., Law, B. M. H., Ng, M. S. N., Chan, D. N. S., So, W. K. W., Wong, C. L., \& Chan, C. W. H. (2020). A review of psychological issues among patients and healthcare staff during two major coronavirus disease outbreaks in China: Contributory factors and management strategies. International Journal of Environmental Research and Public Health, 17(18), 1-17. https://doi.org/10.3390/ijerph17186673

Emaliyawati, E., Widiasih, R., Sutini, T., Ermiati, E., \& Rahayu, U. (2020). Nurses' Reflections on Challenges and Barriers of Communication in the Intensive Care Unit: A Phenomenology Study. Jurnal Keperawatan Padjadjaran, 8(1), 65-73. https://doi. org/10.24198/jkp.v8i1.1190

Findyartini, A., Kambey, D. R., Yusra, R. Y., Timor, A. B., Khairani, C. D., Setyorini, D.,
\& Soemantri, D. (2019). Interprofessional collaborative practice in primary healthcare settings in Indonesia: A mixed-methods study. Journal of Interprofessional Education and Practice, 17, 100279. https://doi. org/10.1016/j.xjep.2019.100279

Galedar, N., Toulabi, T., Kamran, A., \& Heydari, H. (2020). Exploring nurses' perception of taking care of patients with coronavirus disease (COVID-19): A qualitative study. Nursing Open, 8(1), 171179. https://doi.org/10.1002/nop2.616

Gunawan, J., Juthamanee, S., \& Aungsuroch, Y. (2020). Current Mental Health Issues in the Era of Covid-19. Asian Journal of Psychiatry, 51(April), 1-3. https://doi.org/10.1016/j. ajp.2020.102103

Huang, L., Lin, G., Tang, L., Yu, L., \& Zhou, Z. (2020). Special attention to nurses' protection during the COVID-19 epidemic. Critical Care, 24(1), 10-12. https://doi. org/10.1186/s13054-020-2841-7

Karimi,Z.,Fereidouni,Z.,Behnammoghadam, M., Alimohammadi, N., Mousavizadeh, A., Salehi, T., ... Mirzaee, S. (2020). The Lived Experience of Nurses Caring for Patients with COVID-19 in Iran: A Phenomenological Study. Risk Management and Health Care Policy, 13, 1271-1278. https://dx.doi. org/10.2147\%2FRMHP.S258785

Lake, E. T., Germack, H. D., \& Viscardi, M. K. (2017). sectional study of US hospitals. BMJ Quality \& Safety, 25(7), 535-543. https://doi.org/10.1136/bmjqs-2015-003961. Missed

Liu, Q., Luo, D., Haase, J. E., Guo, Q., Wang, X. Q., Liu, S., ... Yang, B. X. (2020). The experiences of health-care providers during the COVID-19 crisis in China: a qualitative study. The Lancet Global Health, 8(6), e790-e798. https://doi.org/10.1016/S2214109X(20)30204-7

Ornell, F., Halpern, S. C., Paim Kessler, F. H., \& de Magalhães Narvaez, J. C. (2020). The impact of the COVID-19 pandemic on the mental health of healthcare professionals. 
Indah Sri Wahyuningsih: The Nurses' Experience during the Caring of Coronavirus (COVID-19) Patients

Cadernos de Saude Publica, 36(4). https:// doi.org/10.1590/0102-311X00063520

Satgas Penanganan COVID-19. Peta Sebaran COVID 19. Retrieved March 24, 2020, from www.covid19.go.id

Polit, D. ., \& Hungler, B. (2012). Nursing Generating and Assesing VidenceFor Nursing Practise (Eight Edit).

Raurell-Torreda, M. (2020). Management of Icu Nursing Teams During the Covid-19 Pandemic. Enfermeria Intensiva, 31(2), 49-51. https://doi.org/10.1016/j. enfi.2020.04.001

Ross, A., Bevans, M., Brooks, A. T., Gibbons, S., \& Wallen, G. R. (2017). Nurses and HealthPromoting Behaviors: Knowledge May Not Translate Into Self-Care. AORN Journal, 105(3), 267-275. https://doi.org/10.1016/j. aorn.2016.12.018

Schwartz, J., King, C. C., \& Yen, M. Y. (2020). Protecting healthcare workers during the Coronavirus Disease 2019 (COVID-19) outbreak: Lessons from Taiwan's severe acute respiratory syndrome response. Clinical Infectious Diseases : An Official Publication of the Infectious Diseases Society of America, 71(15), 858-860. https://doi.org/10.1093/cid/ ciaa255.
Sun, N., Wei, L., Suling, S., Jiao, D., Song Bsc, R., Ma Msc, L., ... Wang Bsc, H. (2020). Qualitative Study: Experienced of Caregivers During Covid19. American Journal of Infection Control, 48(6), 592-598. https://doi.org/10.1016/j.ajic.2020.03.018

Wibowo, Bambang, Widyastoeti. Tri Hesty, Satari, H. (2020). Dokumen resmi 8 april 2020 .

Wu, W., Zhang, Y., Wang, P., Zhang, L., Wang, G., Lei, G., ... Luo, M. (2020). Psychological stress of medical staffs during outbreak of COVID-19 and adjustment strategy. Journal of Medical Virology, 92(10), 1962-1970. https://doi.org/10.1002/jmv.25914

Wulandari, T. S., \& Ismail, S. (2019). Exploring Nurses' Experience of Managing Attention and Mood in Post-Stroke Patients: A Qualitative Study. Jurnal Keperawatan Padjadjaran, 7(2). https://doi.org/10.24198/ jkp.v7i2.1000.

Xie, J., Tong, Z., Guan, X., Du, B., Qiu, H., \& Slutsky, A. S. (2020). Critical care crisis and some recommendations during the COVID-19 epidemic in China. Intensive Care Medicine, 46(5), 837-840. https://doi. org/10.1007/s00134-020-05979-7 